\title{
Relationships Among Therapist Empathy and Authoritarianism and a Therapist's Prognosis
}

Carol Dubnicki

Loyola University Chicago

Follow this and additional works at: https://ecommons.luc.edu/luc_theses

Part of the Psychology Commons

\section{Recommended Citation}

Dubnicki, Carol, "Relationships Among Therapist Empathy and Authoritarianism and a Therapist's Prognosis" (1975). Master's Theses. 2847.

https://ecommons.luc.edu/luc_theses/2847

This Thesis is brought to you for free and open access by the Theses and Dissertations at Loyola eCommons. It has been accepted for inclusion in Master's Theses by an authorized administrator of Loyola eCommons. For more information, please contact ecommons@luc.edu. (c) $($ ) $\Theta \Theta$

This work is licensed under a Creative Commons Attribution-Noncommercial-No Derivative Works 3.0 License. Copyright $\odot 1975$ Carol Dubnicki 
THE RELATIONSHIPS BETWEEN THERAPIST EMPATHY AND AUTHORITARIANISM AND A THERAPIST'S PROGNOSIS

by

Carol Dubnicki

A Thesis Submitted to the Faculty of the Graduate School of Loyola University of Chicago in Partial Fulfillment of the Requirements for the Degree of Master of Arts 


\section{ACKNOWLEDGMENTS}

The author wishes to express her appreciation to Dr. James Johnson and Dr. Thomas Petzel both of the Department of Psychology, Loyola University of Chicago for their help in the preparation of this thesis. Thanks is also due to Dr. Arthur Johnson of Hines Veterans Administration Hospital for his helpful suggestions and to those 25 psychologists who served as subjects for this study. 


\section{VITA}

Carol Dubnicki was born February 6, 1951 in Buffalo, New York.

She attended grade schools in Depew, New York and graduated from Depew High School in June, 1968. She received her Bachelor of Arts degree in psychology from Canisius College, Buffalo, New York in June, 1972. In September, 1972 she began graduate studies at Loyola University, Chicago, Illinois.

She has been a psychology trainee at the west side and, presently, Hines Veterans Administration Hospitals since October, 1972 and also received training in clinical psychology at Chicago's Alcoholic Treatment Center from June through September, 1974. 
ACKNOWLEDGMENTS $\ldots \ldots \ldots \ldots \ldots \ldots \ldots \ldots \ldots \ldots \ldots \ldots \ldots \ldots \ldots \ldots \ldots$

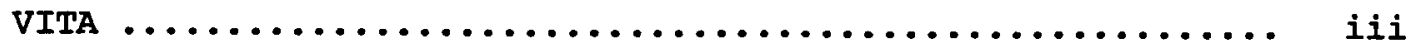

LIST OF TABLES $\ldots \ldots \ldots \ldots \ldots \ldots \ldots \ldots \ldots \ldots \ldots \ldots \ldots \ldots \ldots \ldots \ldots$ v

Chapter

I. INTRODUCTION TO THE PROBLEM AND A REVIEW

OF RELEVANT LITERATURE .................... 1

Factors of Interest Influencing the

Formation of a Therapist's Prognosis ........... 5

II. STATEMENT OF THE PROBLEM $\ldots \ldots \ldots \ldots \ldots \ldots \ldots \ldots \ldots \ldots \ldots$.

III. METHOD $\ldots \ldots \ldots \ldots \ldots \ldots \ldots \ldots \ldots \ldots \ldots \ldots \ldots \ldots \ldots \ldots \ldots \ldots \ldots$

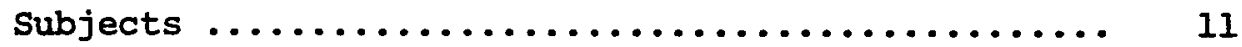

Task Materials and Measures ................... 11

Procedure ............................ 14

IV. RESULTS $\ldots \ldots \ldots \ldots \ldots \ldots \ldots \ldots \ldots \ldots \ldots \ldots \ldots \ldots \ldots \ldots \ldots$

v. DISCUSSION $\ldots \ldots \ldots \ldots \ldots \ldots \ldots \ldots \ldots \ldots \ldots \ldots \ldots \ldots \ldots \ldots . \ldots \ldots$

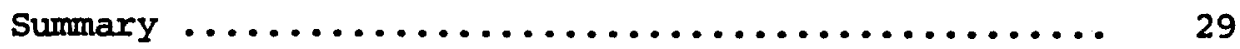

REFERENCE NOTES $\ldots \ldots \ldots \ldots \ldots \ldots \ldots \ldots \ldots \ldots \ldots \ldots \ldots \ldots \ldots \ldots \ldots \ldots$

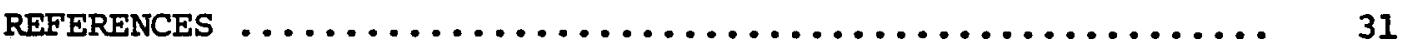




\section{IIST OF TABLES}

Table

Page

1. Multiple Regression Analysis of Prognosis

Variable 1 (judged degree of disturbance)

2. Multiple Regression Analysis of Prognosis

Variable 4 (overall prognosis)

3. Mean and Standard Deviation for Each of

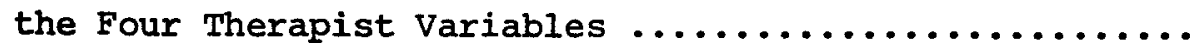

4. Normative Data for Hogan Empathy Scale

(all male samples) $\ldots \ldots \ldots \ldots \ldots \ldots \ldots \ldots \ldots \ldots \ldots \ldots \ldots$

5. Normative Data for Rokeach Dogmatism

Scale (Form E) 


\title{
INTRODUCTION TO THE PROBLEM AND A
}

\author{
REVIEW OF RELEVANT LITERATURE
}

It is agreed that the way in which a therapist perceives his client affects the outcome of therapy. Frieda Fromm-Reichman (1950) has noted that the anxiety induced in the therapist by the client influences therapy in that it appears to have an inverse relationship with the client's sense of self-esteem. Fromm-Reichman has also mentioned that a therapist's liking or disliking for a client may influence the outcome of therapy.

A number of investigators have been concerned with the relationship of the therapist's prognosis for the patient with the outcome and duration of therapy. Strupp and Luborsky (1962) have noted that a therapist's belief about a patient's prognosis seems to be a determinant of the prognosis. It was shown, in a study using 55 psychiatrists and 55 psychologists as subjects, that a therapist's expectations regarding therapy outcome can affect his offering of therapeutic conditions (Strupp, 1958). Each therapist watched films of initial interviews and made "vicarious" comments about each

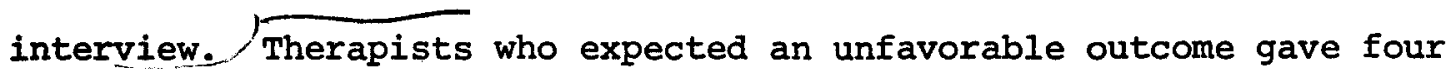
times as many "cold" responses as those therapists who expected a favorable outcome. Therauthor concluded that when the therapist expected a poor outcome his responses were more likely to be "colder" 
and less therapeutic than when the therapist expected a good outcome.

In a study by Goldstein (1960) 15 patients were divided into a group $(\mathrm{N}=11)$ who perceived their problems as improving over the therapy sessions and a group $(N=4)$ who felt their problems had intensified (no allowance was made for patients who felt their problems had remained at the same intensity as when they had begun therapy). The initial prognostic expectancies of the therapists for these two groups were compared. $\int$ It was found that the therapists for those patients who perceived more positive change in themselves during therapy had expected significantly more patient improvement than did the therapists for the patients who felt their problems had intensified. It was also found that therapist prognostic expectancy varied positively and significantly with the length of the therapeutic series. Goldstein (1962) has suggested that the significant difference found is not simply a reflection of accuracy of prognosis; "It is assumed, instead, that such psychotherapist expectancies are in fact communicated to the patient, color their interactions, influence their relationship and, thus effect the degree of patient improvement" (p. 39).

Erica Chance (1959) carried out research which seemed to demonstrate a relationship between patient change and therapist expectation of change. This relationship is somewhat confounded in that, of the six therapists taking part in the study, three were labeled as experienced and three as inexperienced. Although there were no differences in the types of cases assigned, it was found that the experienced therapists tended to have more optimistic prognostic 
expectancies of their clients than the inexperienced therapists; also, "It was demonstrated that the three experienced therapists brought about more positive change in their patients than the three inexperienced therapists..." (p. 114).

The therapist's perception of his client or his prognostic expectation, again, are assumed to influence therapy outcome. Perhaps this relationship can be further clarified if the factors that influence the formation of a therapist's prognosis are considered. It is possible that some of these factors are more influential than others regarding outcome of therapy.

In a survey of psychotherapy research findings, Bergin (1966) digests his findings into six broad conclusions, one of them being, "Therapeutic progress varies as a function of therapist characteristics such as warmth, empathy, adequacy of adjustment, and experience" (p. 239) .

Truax and Carkhuff (1967) have presented an excellent review of the literature dealing with the importance of empathy, warmth and genuineness in a therapeutic relationship. The number of studies exploring the relationship of these variables with therapy outcome is, indeed, sizable. In essence, the great majority of studies seem to suggest that positive relationship exists between the therapist variables of empathy, warmth, and genuineness and constructive personality change in the client. It is interesting to note that these findings apply to a wide variety of therapists, having a wide variety of theoretical orientations, working with $\hat{a}$ wide variety of 
clients including psychiatric patients-both neurotic and psychotic in- and out-patients, juvenile delinquents, and college students. It was also suggested that these findings hold true in a variety of therapeutic settings including both individual and group therapy. The authors present a number of tables which summarize much of the data they present.

Some studies finding a positive relationship between empathy (with some studies examining warmth and/or genuineness in addition to empathy) and therapy outcome using a variety of methods and measures $v$ include Barrett-Lennard, 1962; Betz, 1963a, 1963b; Bergin and Solomon, 1963; Carkhuff and Truax, 1965a, 1965b; Cartwright and Lerner, 1963; Dickenson and Truax, 1966; Dombrow, 1966; Lesser, 1961; Lorr and McNair, 1966; Tomlinson, 1962; Truax, 1961a, 1961b, 1962, 1963, 1966; Truax and Carkhuff, 1964, 1965; Truax, Carkhuff, and Kodman, 1965; Truax and Wargo, 1966; Truax, Wargo, Frank, Imber, Battle, HoehnSaric, Nash, and Stone, 1966; Truax, Wargo, and Silber, 1966; Truax and Wargo, Note 2, Note 3; Truax, Wargo, and Carkhuff, Note 4.

Although not much research has been done on the relationship between adequacy of therapist adjustment and progress in therapy, present findings suggest that those therapists who are more anxious, U conflicted, defensive, or "maladjusted" are least likely to promote $v$ change in their clients (Bergin, 1966).] A number of studies utilizing supervisor and client ratings of the therapist's competence and also those utilizing the therapist's actual in-therapy behavior and the patient's response to it as a criterion of competence have found a 
negative relation between the therapist's judged competence and his anxiety or maladjustment (Arbuckle, 1956; Bandura, 1956; Bandura, Lipsher, \& Miller, 1960; Bergin \& Solomon, 1963; Winder, Ahmad, Bandura, \& Rau, 1962). In addition, it was found by Bergin and Solomon that measures of the therapist's degree of personal disturbance correlate negatively with his level of empathy as measured by tape recordings of psychotherapy interviews. Also, a positive correlation was found between measures of personality strength and degree of empathy. Ratings of therapist anxiety level correlated negatively with independent ratings of therapeutic competence.

Another factor, briefly mentioned earlier, that is a probable contributor toward the formation of a prognosis is therapist experience. It seems to be generally held that more experienced therapists are more successful (Barrett-Lennard, 1962; Cartwright \& Vogel, 1960; Chance, 1959; Fiedler, 1950a, 1950b, 1951) and possibly tend to assign more "optimistic" prognoses than less experienced therapists (Chance, 1959).

Factors of Interest Influencing the Formation of a Therapist's Prognosis

Before continuing, the client based factors influencing therapist prognosis should be noted. Hunt and Jones (1962) have listed the part-stimuli which provide cues for clinical judgment as: (1) biographical data, (2) test scores, and (3) behavioral measures. The main focus of this paper is on the part-stimuli influencing clinical judgment for which the therapist is the source. The specific 
part-stimuli of interest are personality factors of the therapist. The personality factors to be studied are empathy and authoritarianism. It is assumed that these factors will not only affect the prognosis a therapist makes, but will also influence the course of therapy and its eventual outcome.

Rogers (1957) considers empathic understanding during therapy to be a necessary condition for constructive personality change to occur. Some past findings concerning the relationship between empathy and outcome of therapy have been mentioned. More recent studies focusing on the relationship between empathy and outcome of therapy have also found the positive relationship mentioned earlier (Gladstein, 1970; Holder, Carkhuff, \& Berenson, 1967; Hountras \& Anderson, 1969; Mullen, 1970; Mullen \& Abeles, 1971; Shapiro, 1969; Stoffer, 1968). Worth noting here is the study by Holder et al. which utilized a group of clients functioning at both high and low levels of empathy, respect, genuineness and concreteness. A significant relationship was found between depth of self-exploration of low-functioning clients and the level of the above four conditions offered by the counselor while the intrapersonal exploration of the high-functioning clients continued, regardless of the level of these conditions offered by the counselor. Also, depth of self-exploration was found to be significantly higher for high-functioning clients. Thus, although a positive relationship has been generally found, there may be certain types of patients where it is especially outstanding. There have been a few studies concerned with the relationship 
between therapist authoritarianism and outcome of therapy. The findings have been equivocal. Stoffer (1968) found that level of helper dogmatism was not related to therapy outcome with elementary school children.

One investigation was designed to determine, in part, whether authoritarianism was negatively related to counselor effectiveness and whether authoritarianism was significantly diminished through personal involvement in group counseling experiences (Mitchell, 1972). Results indicated that dogmatism is not significantly related to counselor effectiveness, but that authoritarianism significantly diminished with group counseling experiences. This last finding is an important one to note as it indicates that counseling experience may be a possible confounding variable in the investigation of the relationship between authoritarianism and therapy outcome. Mullen and Abeles (1971) found that more experienced therapists tend to be able to attain higher levels of empathy and to avoid therapeutic conditions of extremely low levels of empathy. Thus, experience is probably an intervening variable in the relationship between empathy and therapy outcome as well.

Joure (1970), in a study of T-groups, attempted to examine the possible differential changes with Lewinian (equalitarian trainer who acts like a group member) vs. Clinical (high status expert-authority figure who is personally aloof from the participants) trainer styles on participants with high and low dogmatic personality orientations. Although the relationship could not be tested, the data suggested 
that the two trainer styles (non-authoritarian vs. authoritarian) had differential effects on high and low dogmatics. As with the variable of empathy, the relationship between counselor authoritarianism and therapy outcome may be more noticeable with different groups of patients. This becomes more evident upon examination of the findings of Gaines (1972). In his study investigating the relationship between authoritarianism in military designated "counselors" (senior enlisted men who had little formal training as counselors but were experienced instructors/supervisors) and subsequent grade performance of the students counseled, it was concluded that high authoritarian counselors were less effective than low authoritarian counselors. It was noted, however, that the magnitude of the relationship and the selection ratio were not large.

It is assumed that numerous factors play a part in determining the outcome of therapy and hence also a therapist's prognosis. Empathy and authoritarianism have been singled out for examination here. The literature shows that closely tied in with these factors are the variables of experience and the type of individuals receiving therapy. It is hoped that the paradigm utilized herein will minimize the confounding effects of these last two variables. 
The question examined in the present study is whether a relationship exists between empathy and/or authoritarianism and the prognosis a therapist comes to make for his client. The studies most relevant to the problem under consideration here are those relating (1) prognosis and therapy outcome, and (2) therapist personality and therapy outcome; these studies have been reviewed in Chapter I of this research report. The hypotheses explored were derived by extrapolation from the relevant research findings.

It has been previously indicated that there appears to be a rather strong relationship between a therapist's prognosis and the outcome of therapy. The literature contains, at present, no studies which specifically attempt to relate the personality factor of therapist empathy with the prognosis the therapist makes for his client. If it is true that there exists a positive relationship between prognosis and outcome of therapy, and if it is also true that a positive relationship exists between therapist empathy and outcome of therapy, then it is possible that a positive relationship between therapist empathy and therapist prognosis exists.

There are presently in the literature no studies which specifically attempted to investigate the relationship between therapist authoritarianism and therapist prognosis. If it is true 
that there exists a positive relationship between prognosis and outcome of therapy, and if it is also true that there is a negative relationship between therapist authoritarianism and outcome of therapy, then it is possible that a negative relationship between therapist authoritarianism and therapist prognosis exists.

The hypotheses are: (1) There is a positive relationship between therapist empathy and therapist prognosis; and (2) there is a negative relationship between therapist authoritarianism and therapist prognosis. 


\section{CHAPTER III}

METHOD

\section{Subjects}

Twenty-five male psychologists having a Ph.D. in psychology and currently functioning as therapists served as subjects. The majority of these subjects were employed at Veterans Administration hospitals. They were first questioned for previous experience with the scales used. Those with no past experience with these scales remained as subjects in the study.

Task Materials and Measures

The scale used to measure empathy was the Hogan Empathy Scale (Hogan, 1969).

The Rokeach Dogmatism Scale, Form E was used to measure authoritarianism (Rokeach, 1960).

The original scale used to measure prognosis for therapy was the following:

We are interested in the kinds of judgments people make on minimal information and would like you to make the best judgment you can based on the given information. Circle the most appropriate point on the scale. Carefully read labels because instructions are not the same throughout the test. Remember be sure to circle only one number. N.B. Organicity can be ruled out.

Mr. J., who is 48, gradually began spending less and less time with his wife and two schoolage children. Now, everyday he comes home from work, eats dinner and retires to his room where he spends the 
remainder of the evening in solitude, saying almost nothing to his family.

How disturbed is he?

\begin{tabular}{lllllll}
\hline 1 & 2 & 3 & 4 & 5 & 6 & 7
\end{tabular}

$\begin{array}{llll}\text { not at all } & \text { mildly } & \text { moderately } & \text { severely } \\ \text { disturbed } & \text { disturbed } & \text { disturbed } & \text { disturbed }\end{array}$

How long will he require hospitalization as compared to expectation in a general psychiatric population?

\begin{tabular}{|c|c|c|c|c|c|}
\hline$\overline{1}$ & 2 & 3 & 4 & 5 & 6 \\
\hline $\begin{array}{l}\text { indefin- } \\
\text { itely }\end{array}$ & $\begin{array}{l}\text { much } \\
\text { longer } \\
\text { than } \\
\text { avg. }\end{array}$ & $\begin{array}{l}\text { longer } \\
\text { than } \\
\text { avg. }\end{array}$ & $\begin{array}{l}\text { about } \\
\text { avg. }\end{array}$ & $\begin{array}{l}\text { shorter } \\
\text { than } \\
\text { avg. }\end{array}$ & $\begin{array}{l}\text { much } \\
\text { shorter } \\
\text { than } \\
\text { avg. }\end{array}$ \\
\hline
\end{tabular}

How long will he require therapy within your particular therapeutic orientation?

\begin{tabular}{ccccccc}
\hline 1 & 2 & 3 & 4 & 5 & 6 & 7 \\
none & $\begin{array}{l}\text { much } \\
\text { shorter } \\
\text { than } \\
\text { avg. }\end{array}$ & $\begin{array}{l}\text { shorter } \\
\text { than } \\
\text { avg. }\end{array}$ & about & $\begin{array}{l}\text { longer } \\
\text { than } \\
\text { avg. }\end{array}$ & $\begin{array}{l}\text { much } \\
\text { longer } \\
\text { than } \\
\text { avg. }\end{array}$ &
\end{tabular}

What is his prognosis?

\begin{tabular}{lllllll}
\hline 1 & 2 & 3 & 4 & 5 & 6 & 7
\end{tabular}

hopeless very poor average good $\begin{aligned} & \text { very excellent } \\ & \text { good }\end{aligned}$

(The above scales followed each case history. Each case and its accompanying scales were on a separate page and the pages were randomly ordered for each subject.) 
Miss S., who is 24, has been disappointed in love several times. She has decided that men are no good and acts accordingly. Although she has been asked out many times during the past year, she rudely refuses each time. All but superficial contact with males is avoided.

George H. is 19 years old. He claims that his high school training has made him the man he is today. He believes he is an electronics genius and has $x$-ray vision.

James J. (48) has lost his last two jobs due to arguments with his foremen, whom he believes have somehow chosen to deliberately annoy him. He is prone to increasingly violent physical outbreaks with his wife and children.

Mrs. M's (age 42) children state that she has begun talking to herself and is prone to be very forgetful. She has almost daily crying spells.

June H. (32) has been unable to leave her house for several months without feeling an overwhelming sense of panic. She cannot explain why she feels this way. She has had to quit her teaching job because of this.

Louis B. (43) has been a passive individual most of his life. His policy has been never to argue. He has become increasingly nervous and is now unable to function satisfactorily at work.

Mr. H. (49) has frequently been bothered by what he considers to be sinful thoughts about women. Consequently, he has decided to fast to atone for his sins. He has eaten only buttered toast and tea for one month.

George K., a senior in high school, confessed his intent to commit suicide to one of his teachers. His parents, upon learning this, rushed him to the clinic. He refuses to further discuss the matter.

Mary J. (22) has become increasingly sloppy about her appearance over the past year. She now giggles at inappropriate times and generally displays inappropriate affect. She has no job and lives with her parents.

A demographic questionnaire requesting specification of age, degree, and number of years experienced was utilized.

Task materials consisted of a manila envelope containing the 
measurement scales, a sheet of printed instructions, and a stamped envelope addressed to the investigator. $\underline{\text { Procedure }}$

Potential subjects were individually contacted and given a brief description of the research design. Each potential subject was informed that any task materials completed and returned by him would remain anonymous to the researcher, since the researcher's advisor, who was not aware of the identification of the subjects, would detach the demographic sheet from the remainder of the data and code it before the researcher examined the data. Finally, the potential subjects were told that after tentatively agreeing to participate as subjects and examining the task materials, they could still choose not to participate and were asked to return the task materials if this was the case.

Those psychologists tentatively agreeing to serve as subjects were given the envelope containing the measurement scales, printed instructions, and stamped envelope. The instructions read as follows: "Please complete the task materials at one sitting. This should take you no longer than one hour. When complete, enclose them in the stamped-addressed envelope included and drop it in the mail. Please do this as soon as possible. Thank you."

After one week each subject was contacted and reminded to mail his envelope if he had not yet done so. After each consecutive week each subject was contacted and so instructed, until all the envelopes had been returned. Subjects were informed that they would continue 
15

to be contacted, even though they may have mailed their envelopes, since the returned task materials were anonymous. 
CHAPTER IV

\section{RESULTS}

The data were analyzed using the Pearson product-moment correlation. Specifically, a correlation was run between (1) the Hogan Empathy Scale and each of the four prognostic scales, (2) the Rokeach Dogmatism Scale and each of the four prognostic scales, and (3) the age and experience variables and the Hogan Empathy Scale and the Rokeach Dogmatism Scale as well as each of the four prognostic scales. Multiple regression analyses were carried out to determine whether different factor weights exist in the prediction of the prognosis variables.

The first hypothesis, that there is a positive relationship between the therapist personality trait of empathy and therapist prognosis, was confirmed for the first and fourth prognosis variables. A significant correlation was found between the therapist variable of empathy and the first and fourth prognosis variables dealing with (I) perception of degree of disturbance and (4) overall prognosis for treatment. The correlation coefficients were $\underline{r}(23)=-.43$ and .39 , $p<.05$ respectively, indicating that the more empathic the therapist, the less disturbed he will perceive an individual as being, and that the more empathic the therapist, the better the prognosis he will assign an individual. The relationship between therapist empathy and prognosis for the first and fourth prognosis variables was 
essentially a positive one (the correlation co-efficient for therapist empathy and the first prognosis variable appears negative since the scale for that variable moves in the direction from "not at all disturbed" to "severely disturbed"). No significant relationship was found between therapist empathy and the second nor third prognosis variables dealing with (2) length of required hospitalization and (3) length of required psychotherapeutic treatment $(\underline{r}(23)=-.06$ and -.08 respectively).

The second hypothesis, that there is a negative relationship between therapist authoritarianism and therapist prognosis was not confirmed. No significant correlation was found between therapist authoritarianism and any of the four prognosis variables $(\underline{r}(23)=.24$, $-.06,-.05$, and -.18 respectively).

When multiple regression analyses were carried out using the therapist demographic variables of age and number of years experience as well as the variables of authoritarianism and empathy, a moderate relationship was obtained for the first and fourth prognosis variables $\left(\underline{r}^{2}=.38\right.$ and .29 respectively--See Tables $I$ and 2$)$. Examination of Table 1 reveals, by deletion of the least informative variable of authoritarianism, that empathy, age, and number of years experience are most informative (and necessary in order that the value of $\underline{r}^{2}$ be maintained) in the prediction of a therapist's perception regarding degree of disturbance of an individual. This indicates that the more empathic, older and less experienced the therapist, the less disturbed he will perceive an individual. 
Table I

Multiple Regression Analysis of Prognosis Variable 1

(judged degree of disturbance)

$\mathrm{X}$

1 (empathy)

2 (authoritarianism)

3 (age)

4 (\# yrs. experience)

$x$

1 (empathy)

3 (age)

4 (\# yrs. experience)

$\mathrm{X}$

1 (empathy)

4 (\# yrs. experience)

$\mathbf{x}$

1 (empathy)
F

7.89

.01

2.13

3.46

F

8.52

3.13

5.22

$r^{2}=.38$

df $=3,21$ $r^{2}=.38$

df $=4,20$

F

6.76

$r^{2}=.29$

2.90

$\mathrm{df}=2,22$

$\mathbf{F}$

5.47

$r^{2}=.19$

df $=1,23$

Note. The backward elimination method has been utilized in both Tables 1 and 2. At each successive stage partial $F$ tests are constructed for every coefficient and the variable with the smallest partial $F$ is deleted. It is recognized that although distributions of partial Fs are not known, it is customary to proceed in this fashion (Johnson, Note 1 ). 
Table 2

Multiple Regression Analysis of Prognosis Variable 4 (overall prognosis)

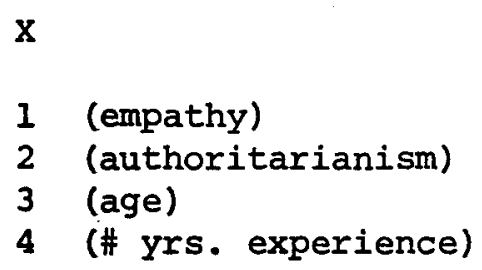

$\mathrm{x}$

1 (empathy)

2 (authoritarianism)

4 (\# yrs. experience)

$\mathrm{x}$

1 (empathy)

4 (\# yrs. experience)

$x$

1 (empathy)

\section{F}

4.77

.29

.04

.11

$\mathbf{F}$

5.32

.27

3.07

$r^{2}=.29$

df $=3,21$

F

5.69

3.69

$r^{2}=.28$

$d f=2,22$

F

4.31

$r^{2}=.16$

$\mathrm{df}=1,23$ 
Examination of Table 2 reveals, by consecutive deletion of the least informative variables, that empathy and number of years experience are most informative (and necessary in order that the value of $\underline{r}^{2}$ be maintained) in the prediction of a therapist's overall prognosis. This indicates that the more empathic and less experienced the therapist, the better the prognosis he would assign to an individual. It is notable that in the multiple regression analyses for both the first and fourth prognosis variables, therapist empathy accounted for much more of the variance than the other three therapist variables.

The mean and standard deviation for each of the four therapist variables are presented in Table 3. Normative data regarding mean and standard deviation for the Hogan Empathy Scale and Rokeach Dogmatism Scale are presented in Tables 4 and 5 respectively. It appears that the therapist empathy scale mean from the present sample most closely resembles that of Hogan's sample of medical students. The therapist authoritarian scale mean from the present study falls far below the means of the normative samples presented by Rokeach, thus indicative of a lesser degree of authoritarianism than in Rokeach's normative samples. 


\section{Table 3 \\ Mean and Standard Deviation for Each of the \\ Four Therapist Variables}

$\mathrm{X}$

empathy (Hogan Empathy Scale)

authoritarianism (Rokeach

Dogmatism Scale, Form E)

age

\# years experience
$\mathbf{M}$

SD

42

5

119

22.1

42

11.3

12.5

10.2 
Table 4

Normative Data for Hogan Empathy Scale (all male samples)

Group

1. Psychology Majors

2. Education Abroad Students

3. Medical students

4. Research Scientists

5. College Students (all levels)

6. Honor Students in Engineering

7. Military officers

8. Architects

9. Junior High School Students (Grades $7 \& 8$ )
N

24

18

70

45

90

66

100

124

51

92

100
$S D$

5.2

4.8

5.3

5.4

4.7

38.0

6.4

37.7

7.1

36.8

5.3

31.0

5.0

10. Prison Inmates

30.4

11. Young Delinquents

29.1

Note. The above data are from Hogan, 1969. 
Table 5

Normative Data for Rokeach Dogmatism Scale (Form E)

Group

1. English Colleges

2. English Workers

3. Ohio State University I

4. Ohio State University II

5. Ohio State University III

6. Ohio State University IV

7. Ohio State University $V$

8. VA Domiciliary
$\mathbf{N}$

80

60

22

28

21

29

58

80
$\mathbf{M}$

152.8

175.8

142.6

143.8

142.6

141.5

141.3

183.2
SD

26.2

26

27.6

22.1

23.3

27.8

28.2

26.6

Note. The above data are from Rokeach, 1960. 
CHAPTER V

\section{DISCUSSION}

The first hypothesis, that there is a positive relationship between the therapist personality trait of empathy and therapist prognosis, was supported only regarding the first and fourth prognosis variables. The second hypothesis, that there is a negative relationship between therapist authoritarianism and therapist prognosis, was not supported. The relationship between empathy and perceived degree of disturbance was a negative one, implying that the more empathic the therapist, the less disturbed he will perceive an individual. The relationship between empathy and overall prognosis was a positive/ one, implying that the more empathic the therapist, the better the prognosis he will assign to an individual.

When the demographic variables of age and number of years experience were added to therapist empathy and authoritarianism in multiple regression analyses, it was found that therapist empathy, age, and number of years experience were most informative in predicting the therapist's perception of a given individual's degree of disturbance. At first glance it appears that the more empathic, older, and less experienced the therapist, the less disturbed he will perceive an individual. This particular result seems inexplicable, especially since the simple linear correlation for age and number of years experience is .94 . It should be remembered that regression analysis 
of survey-type data can at best lead to a predictive equation with the efficiency of the obtained predictive equation depending upon the environment being the same as that at the time the original prediction was made. Attempts to interpret individual co-efficients, as in the above instance, may not be productive because all co-efficients are biased by the influence of variables not considered in the regression equation. The fact that a co-efficient is not what was expected does not mean that the variables are meaningless. Examination of these co-efficients in survey research can be used as insights to do new experiments, but results from experiments should not be set aside because the co-efficients do not meet pre-experimental expectations. "To find out what happens to a system when you interfere with it you have to interfere with it (not just passively observe it)" (Box, 1966, p. 629).

It is possible that the results of the regression analysis for the first prognosis variable (degree of disturbance) may, in part, be due to the fact that the majority of the subjects were drawn from the same institution and consequently may share similar biases in viewing patients. In order to discover if the results of this regression analysis are biased or if this combination of variables is indeed the best predictor of perception of degree of disturbance, a number of surveys of this type could be done, using for each study as radically different a sample of raters as possible. If the results then tend to be similar to those in this study, it would be highly unlikely that this commonality is simply due to the biased character- 
istics of this sample. It is understood that a single survey is not enough to determine a relationship, whereas a single experiment might be all that is needed.

Through regression analysis of the fourth prognosis variable and use of the backward elimination method, it was found that therapist empathy and number of years experience were the best predictors of the therapist's overall prognosis for an individual, such that the more empathic and less experienced the therapist, the better the prognosis he would assign to an individual.

It appears that just as more empathic therapists tend to obtain more successful therapy outcomes, more empathic therapists may assign better prognoses to their patients and perceive them as being less disturbed.

Unlike the study by Mullen et al. (1971) mentioned earlier, no significant correlation was found in the present research between experience and empathy $(\underline{r}(23)=.11)$, nor was a relationship noted between experience and authoritarianism $(\underline{r}(23)=.18)$ as was suggested by Mitchell (1972). The possibility that more experienced therapists would tend to assign more optimistic prognoses to patients than less experienced therapists (Chance, 1959) was not confirmed $(\underline{x}(23)=.26$, $-.19, .37$ and -.30 respectively).

It should be noted that in the present study, although the therapist empathy scores fell into a reasonably distributed range, the range of authoritarianism scores was relatively constricted, with nearly all subjects tending to be more or less non-authoritarian 
according to Rokeach's standardization data. This last finding may, in part, be due to the small sample used. The possibility of some bias exists since the majority of subjects tended to answer the authoritarianism scale items in a socially desirable manner. Finally, the possibility that Ph.D. psychologists as a group may tend to be relatively non-authoritarian, must be considered.

It is interesting to also note that no relationship was found between authoritarianism and empathy. This is somewhat surprising considering the significant relationship Hogan (1969) found between empathy and the California Personality Inventory Dominance Scale $(\underline{r}(68)=.48$ in his sample of medical school applicants and $\underline{r}(49)=.56$ in his sample of female college seniors). The results of the present research, rather, suggest that authoritarianism and empathy tend to be rather independent variables in therapists. Consequently, while the present study does indicate therapist empathy to be positively related to prognosis, this finding is not parallelled with therapist authoritarianism and prognosis. Thus, a therapist might conceivably score anywhere in the range of authoritarianism and still be quite empathic. The lack of relationship between both empathy and prognosis and authoritarianism in this study might also be explained by the constricted range of authoritarianism scores found herein. It may be that relationships do exist between each of these variables and authoritarianism, but this remains to be determined.

The fact that no relationship was found between any of the 
therapist variables and the second and third prognosis variables dealing with (2) length of required hospitalization, and (3) length of required psychotherapeutic treatment, may be due to a certain amount of ambiguity regarding these two variables. The nature of the second prognostic scale makes it somewhat difficult to know what baseline a therapist is using to make his comparison--is it other patients with a similar diagnosis or is it a general psychiatric population composed of patients of various diagnostic categories or is it the patients in his particular facility? A similar ambiguity exists regarding the third prognostic variable.

Most important to this researcher is the positive relationship found between therapist empathy and prognosis. Since a relationship had also been found between a therapist's prognosis and outcome of therapy (Chance, 1959; Fromm-Reichman, 1950; Goldstein, 1960; Strupp, 1958) and therapist empathy and therapy outcome (Gardner, 1964; Rogers, 1957; Truax \& Carkhuff, 1967; plus numerous other studies mentioned earlier), it was predicted that a positive relationship exists between therapist empathy and prognosis as well. Indeed, this seems to be the case. Perhaps in time we will be placing much greater emphasis on teaching our future therapists how to be more empathic and, perhaps, as a consequence to be more effective in therapy. Further support and refinement of this relationship seems advisable. Holder et al. (1967) suggest that there may be certain types of patients where the relationship between therapist empathy and outcome is especially outstanding as with the low-functioning clients (as 
opposed to the higher-functioning clients) in their sample. Summary

This study investigated the relationship between the therapist personality variables of empathy and authoritarianism and the prognosis a therapist makes. Twenty-five Ph.D. psychologists served as subjects. A positive relationship was found between therapist empathy and prognosis variables dealing with perception of degree of disturbance and overall prognosis. No relationship was found between therapist empathy and the prognosis variables dealing with length of required hospitalization and length of required psychotherapeutic treatment. No relationship was found between authoritarianism and any of the four prognosis variables. One possible explanation of the latter is the constricted range of authoritarianism scores found herein, with the subjects participating in this study tending to score in the non-authoritarian range according to normative data.

Upon examination of the data through multiple regression analysis the following was found: (I) empathy, number of years experience, and age (in that order) are of greatest importance in predicting a therapist's perception of degree of disturbance of an individual; (2) empathy and number of years experience (in that order) are of most importance in predicting a therapist's overall prognosis for an individual. 


\section{REFERENCE NOTES}

1. Johnson, A. Personal communication, March 14, 1975.

2. Truax, C. B., \& Wargo, D. G. Antecedents to outcome in group psychotherapy with juvenile delinquents: Effects of therapeutic conditions, alternate sessions, vicarious therapy pretraining, and patient self-exploration. Unpublished manuscript, University of Arkansas, 1966.

3. Truax, C. B., \& Wargo, D. G. Antecedents to outcome in group psychotherapy with hospitalized mental patients: Effects of therapeutic conditions, alternate sessions, vicarious therapy pretraining, and patient self-exploration. Unpublished manuscript, University of Arkansas, 1966.

4. Truax, C. B., Wargo, D. G., \& Carkhuff, R. R. Antecedents to outcome in group psychotherapy with outpatients: Effects of therapeutic conditions, alternate sessions, vicarious therapy pretraining and patient self-exploration. Unpublished manuscript, University of Arkansas, 1966. 


\section{REFERENCES}

Arbuckle, D. S. Client perception of counselor personality. Journal of Counseling Psychology, 1956, 3 , 93-96.

Bandura, A. Psychotherapist's anxiety level, self-insight, and psychotherapeutic competence. Journal of Abnormal and Social Psychology, 1956, 52, 333-337.

Bandura, A., Lipsher, D. H., \& Miller, P. E. Psychotherapists' approach-avoidance reactions to patients' expressions of hostility. Journal of Consulting Psychology, 1960, 24, 1-8.

Barrett-Lennard, G. T. Dimensions of therapist response as causal factors in therapeutic change. Psychological Monographs, 1962, 76 (43, Whole No. 562).

Bergin, A. E. Some implications of psychotherapy research for therapeutic practice. Journal of Abnormal Psychology, 1966, 7I, 235-246.

Bergin, A. E., \& Solomon, S. Personality and performance correlates of empathic understanding in psychotherapy. American Psychologist, 1963, 18, 393.

Betz, B. J. Bases of therapeutic leadership in psychotherapy with the schizophrenic patient. American Journal of Psychotherapy, $1963, \underline{17}, 196-212$. (a)

Betz, B. J. Differential success rates of psychotherapists with "process" and "non-process" schizophrenic patients. American Journal of Psychiatry, 1963, 11, 1090-1091. 
Box, G. E. P. Use and abuse of regression. Technometrics, 1966, 8, 625-629.

Carkhuff, R. R., \& Truax, C. B. Training in counseling and psychotherapy: An evaluation of an integrated didactic and experiential approach. Journal of Consulting Psychology, 1965 , 29, 333-336. (a)

Carkhuff, R. R., \& Truax, C. B. Lay mental health counseling: The effects of lay group counseling. Journal of Consulting Psychology, 1965, 29, 426-431. (b)

Cartwright, R. D., \& Lerner, B. Empathy: Need to change and improvement with psychotherapy. Journal of Consulting Psychology, $1963,27,138-144$.

Cartwright, R. D., \& Vogel, J. L. A comparison of changes in psychoneurotic patients during matched periods of therapy and no-therapy. Journal of Consulting Psychology, 1960, 24, 121127.

Chance, E. Families in treatment. New York: Basic Books, 1959. Dickenson, W. A., \& Truax, C. B. Group counseling with college underachievers: Comparisons with a control group and relationship to empathy, warmth, and genuineness. Personnel Guidance Journal, 1966.

Dombrow, R. A. A study of the relationship between therapists' empathy for patients and changes in patients' self concepts during therapy. Dissertation Abstracts, 1966, 27 (1-B), 301302 . 
Fiedler, F. E. A comparison of therapeutic relationships in psychoanalytic, nondirective, and Adlerian therapy. Journal of Consulting Psychology, 1950, 14, 436-445. (a)

Fiedler, F. E. The concept of the ideal therapeutic relationship. Journal of Consulting Psychology, 1950, 14, 239-245. (b)

Fiedler, F. E. Factor analyses of psychoanalytic, nondirective, and Adlerian therapeutic relationships. Journal of Consulting Psychology, 1951, 15, 32-38.

Fromm-Reichman, F. Principles of intensive psychotherapy. Chicago: University of Chicago Press, 1950.

Gaines, R. N. Authoritarianism in military designated "counselors" and their effectiveness. Dissertation Abstracts International, $1972, \underline{33}(7-A), 3286$.

Gardner, G. G. The psychotherapeutic relationship. Psychological Bulletin, 1964, 61, 426-437.

Gladstein, G. A. Is empathy important in counseling? Personnel and Guidance Journal, 1970, 48, 823-827.

Goldstein, A. Therapist and client expectation of personality change in psychotherapy. Journal of Counseling Psychology, 1960, 7 $180-184$

Goldstein, A. Therapist-patient expectancies in psychotherapy. New York: Pergammon Press, 1962.

Hogan, R. Development of an empathy scale. Journal ge fonfulting and Clinical Psychology, 1969, 33, 307-316. Holder, T., Carkhuff, R. R., \& Berenson, B. G. Differentialveffects 
of the manipulation of therapeutic conditions upon high- and lowfunctioning clients. Journal of Counseling Psychology, 1967, 14, 63-66.

Hountras, P. T., \& Anderson, D. L. Counselor conditions for selfexploration of college students. Personnel and Guidance Journal, $1969,48,45-48$.

Hunt, W. A., \& Jones, N. F. The experimental investigation of clinical judgment. In A. J. Bacharach (Ed.), Experimental foundations of clinical psychology. New York: Basic Books, Inc., 1962, 26-51.

Joure, S. A. Influence of trainer style and participant personality on $\mathrm{T}$-group change. Dissertation Abstracts International, 1970, 31 $(10-B), 6315$.

Lesser, W. M. The relationship between counseling progress and empathic understanding. Journal of Counseling Psychology, 1961, 8, 330-336.

Lorr, G. M., \& McNair, D. M. Methods relating to evaluation of therapeutic outcome. In L. A. Gottschalk \& A. H. Auerbach (Eds.), Methods of research in psychotherapy. New York: AppletonCentury-Crofts, 1966.

Mitchell, R. A. The effect of group counseling experiences in a didactic classroom setting on selected personality variables and counseling effectiveness. Dissertation Abstracts International $1972, \underline{32}(12-\mathrm{A}), 6765$.

Mullen, J. A. An investigation of the variable of liking in therapy: 
Its relation to the variables of outcome, empathy, and therapist experience. Dissertation Abstracts International, 1970, 31 (3-B), 1546-1547.

Mullen, J. A., \& Abeles, N. Relationship of liking, empathy, and therapist's experience to outcome of therapy. Journal of Counseling Psychology, 1971, 18, 39-43.

Rogers, C. R. The necessary and sufficient conditions of therapeutic personality change. Journal of Consulting Psychology, 1957, 21, 95-103.

Rokeach, M. The open and closed mind: Investigations into the nature of belief systems and personality systems. New York: Basic Books, Inc., 1960.

Shapiro, D. A. Empathy, warmth, and genuineness in psychotherapy. British Journal of Social and Clinical Psychology, 1969, 8 , 350-361.

stoffer, I. An investigation of therapeutic success as a function of genuineness, nonpossessive warmth, empathic understanding, and dogmatism in the helping person. Dissertation Abstracts, $1968, \underline{29}(3-\mathrm{A}), 799$.

Strupp, H. H. The performance of psychiatrists and psychologists in a therapeutic interview. Journal of Clinical Psychology, $1958,14,219-226$.

Strupp, H. H., \& Luborsky, L. (Eds.). Research in psychotherapy. Stanford: Stanford University Press, 1962. Strupp, H. H., Wallach, M. S., \& Wogan, M. Psychotherapy experience 
in retrospect: Questionnaire survey of former patients and their therapists. Psychological Monographs, 1964, 78 (11, Whole No. 588). Tomlinson, T. M. The process of personality change in schizophrenics and neurotics. Brief Research Reports. Wisconsin Psychiatric Institute, University of Wisconsin, 1962, 17.

Truax, C. B. The process of group psychotherapy: Relationships between hypothesized therapeutic conditions and intrapersonal exploration. Psychological Monographs, 1961, 75 (7, Whole No. 511). (a)

Truax, C. B. A scale for the measurement of accurate empathy. Psychiatric Institute Bulletin. Wisconsin Psychiatric Institute, University of Wisconsin, 1961, 1,12 . (b)

Truax, C. B. A tentative scale for the measurement of unconditional positive regard. Psychiatric Institute Bulletin. Wisconsin Psychiatric Institute, University of Wisconsin, 1962, 2, 1. Truax, C. B. Effective ingredients in psychotherapy. Journal of Counseling Psychology, 1963, 10, 256-263.

Truax, C. B. Therapist empathy, warmth, and genuineness and patient personality change in group psychotherapy: A comparison between interaction unit measures, time sample measures, and patient perception measures. Journal of Clinical Psychology, 1966, 22, 225-229.

Truax, C. B., \& Carkhuff, R. R. For better or for worse: The process of psychotherapeutic change. In Recent advances in the study of behavior change. Montreal, Canada: McGill University Press, 1963. 
Truax, C. B., \& Carkhuff, R. R. Significant developments in psychotherapy research. In L. E. Abt \& B. F. Reiss (Eds.), Progress in clinical psychology. New York: Grune and Stratton, 1964. Truax, C. B., \& Carkhuff, R. R. The experimental manipulation of therapeutic conditions. Journal of Consulting Psychology, 1965 , 29, 119-124.

Truax, C. B., \& Carkhuff, R. R. Toward effective counseling and psychotherapy: Training and practice. Chicago: Aldine Publishing Company, 1967.

Truax, C. B., Carkhuff, R. R., \& Kodman, F. Relationships between therapist-offered conditions and patient change in group psychotherapy. Journal of Clinical Psychology, 1965, 21, 327329.

Truax, C. B., \& Wargo, D. G. Psychotherapeutic encounters that change behavior: For better or for worse. American Journal of Psychotherapy, 1966, 22, 499-520.

Truax, C. B., Wargo, D. G., Frank, J. D., Imber, S. D., Battle, C. C., Hoehn-Saric, R., Nash, E. H., \& Stone, A. R. Therapist empathy, genuineness, and warmth and patient therapeutic outcome. Journal of Consulting Psychology, 1966, 30, 395-401.

Truax, C. B., Wargo, D. G., \& Silber, L. D. Effects of high accurate empathy and nonpossessive warmth during group psychotherapy upon female institutionalized delinquents. Journal of Abnormal Psychology, 1966, 71, 267-274. Wargo, D. G. The Barron Ego Strength and LH scales as predictors 
and indicators of change in psychotherapy. Brief Research Reports. Wisconsin Psychiatric Institute, University of Wisconsin, 1962, 21.

Winder, C. L., Ahmad, F. Z., Bandura, A., \& Rau, I. Dependency of patients, psychotherapists' responses, and aspects of psychotherapy. Journal of Consulting Psychology, 1962, 26, 129-134. 


\title{
APPROVAL SHEET
}

The thesis submitted by Carol Dubnicki has been read and approved by the following Committee:

\author{
Dr. James E. Johnson, Chairman \\ Associate Professor, Psychology, Loyola \\ Dr. Thomas P. Petzel \\ Associate Professor, Psychology, Loyola
}

The final copies have been examined by the director of the thesis and the signature which appears below verifies the fact that any necessary changes have been incorporated and that the thesis is now given final approval by the committee with reference to content and form.

The thesis is therefore accepted in partial fulfillment of the requirements for the degree of Master of Arts.
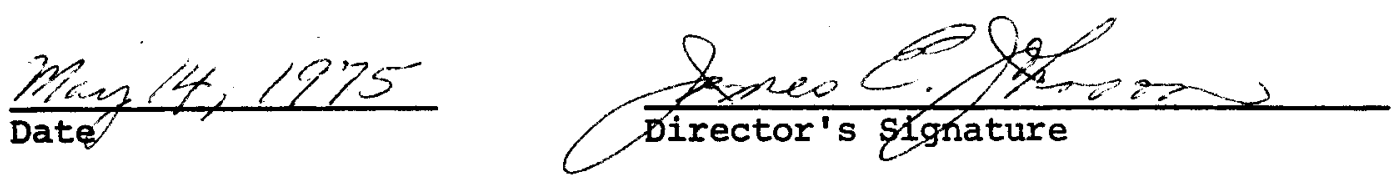